\title{
Diagnosis and Treatment of Bradykinin-Mediated Angioedema: Outcomes from an Angioedema Expert Consensus Meeting
}

\author{
Timothy J. Craig $^{a}$ Jonathan A. Bernstein ${ }^{b}$ Henriette Farkas ${ }^{c}$ \\ Laurence Bouillet $^{d}$ Isabelle Boccon-Gibod ${ }^{d}$ \\ a Penn State University, Hershey Medical Center, Hershey, Pa., ${ }^{b}$ University of Cincinnati Medical Center, Cincinnati, \\ Ohio, USA; 'Semmelweis University, National Angioedema Center, 3rd Department of Internal Medicine, Budapest, \\ Hungary; ${ }^{d}$ Grenoble University Hospital, National Reference Center of Angioedema, Internal Medicine Department, \\ Grenoble, France
}

\section{Key Words}

Angioedema $\cdot \mathrm{C} 1$ inhibitor $\cdot$ Hereditary angioedema .

Treatment $\cdot$ C1-esterase inhibitor

\begin{abstract}
Several types of angioedema exist beyond hereditary angioedema (HAE) types I/II; however, the diagnostic and treatment needs of these conditions are not well understood. Noticeably, there are no licensed treatments available for other forms of angioedema beyond HAE types I/II, and similarly they are unresponsive to conventional antihistamine/glucocorticoid treatment. A group of angioedema experts met in Budapest in May 2013 to discuss such issues, presenting their experience, reviewing available literature and identifying unmet diagnostic and treatment needs in three different angioedema types: HAE with normal C1-inhibitor (C1-INH; previously referred to as type III HAE); nonallergic angiotensin-converting enzyme inhibitor (ACEI)-induced angioedema (ACEI-AAE), and acquired angioedema due to $\mathrm{C} 1-\mathrm{INH}$ deficiency (C1-INH-AAE). The group identified unmet diagnostic and treatment needs in HAE-nC1-INH, C1-INH-AAE and ACEI-AAE, explored remedies and made recommendations on how to diagnose and treat these forms of angioedema. The group discussed the difficulties associated with using
\end{abstract}

diagnostic markers, such as the level and function of $\mathrm{C} 1-\mathrm{INH}$, $\mathrm{C} 1 \mathrm{q}$ and $\mathrm{C} 4$ to reliably diagnose the angioedema type, and considered the use of genetic testing to identify mutations in FXII or XPNPEP2 that have been associated with HAE-nC1INH and ACEI-AAE, respectively. Due to the lack of approved treatments for HAE-nC1-INH, ACEI-AAE and C1-INH-AAE, the group presented several case studies in which therapies approved for treatment of HAE types I/II, such as icatibant, ecallantide and pasteurized, nanofiltered $\mathrm{C} 1-\mathrm{INH}$, were successful. It was uniformly agreed that further studies are needed to improve the diagnosis and treatment of angioedema other than HAE types I/II.

ㄷ) 2014 S. Karger AG, Basel

\section{Introduction}

Hereditary angioedema (HAE) types I/II (HAE with deficient C1-inhibitor, C1-INH, and HAE with dysfunctional C1-INH) are well-characterized forms of HAE, which can be diagnosed by low functional levels of C1INH and, in most cases, have a positive family history. Several treatments exist for HAE types I/II, including C1$\mathrm{INH}$, the $\beta 2$ bradykinin receptor antagonist icatibant, and the kallikrein inhibitor ecallantide, which have been suc-

\begin{tabular}{ll}
\hline KARGER & $\begin{array}{l}\text { ( ) 2014 S. Karger AG, Basel } \\
1018-2438 / 14 / 1652-0119 \$ 39.50 / 0 \quad \text { Karger }\end{array}$ \\
$\begin{array}{l}\text { E-Mail karger@karger.com } \\
\text { www.karger.com/iaa }\end{array}$ & $\begin{array}{l}\text { This is an Open Access article licensed under the terms of the } \\
\text { Creative Commons Attribution-NonCommercial 3.0 Un- } \\
\text { ported license (CC BY-NC) (www.karger.com/OA-license), } \\
\text { applicable to the online version of the article only. Distribu- } \\
\text { tion permitted for non-commercial purposes only. }\end{array}$
\end{tabular}

Correspondence to: Dr. Timothy J. Craig

Penn State University College of Medicine

Hershey Medical Center

Hershey, PA 17033 (USA)

E-Mail tcraig@hmc.psu.edu 
Fig. 1. Mechanism of bradykinin-mediated angioedema. Increased bradykinin levels lead to vasodilation, increased tissue permeability and edema. Degradation of bradykinin is mediated by kininases. ACE, which plays a role in degradation of bradykinin, can be inhibited by ACEIs. Production of bradykinin can be inhibited by ecallantide, which acts on kallikrein, or by C1-INH, which acts to inhibit formation of kallikrein and HMW kininogen. Activation of the bradykinin $\beta 2$ receptor is inhibited by icatibant. In angioedema cases where C1-INH is deficient, treatment with pnfC1-INH or recombinant human $\mathrm{C} 1$-INH replaces endogenous $\mathrm{C} 1-\mathrm{INH}$ to control bradykinin levels. Dashed lines indicate inhibition. ACE = Angiotensin converting enzyme; ACEI = angiotensin converting enzyme inhibitor; HMW = high molecular weight; C1-INH = C1-inhibitor; pnfC1-INH = pasteurized, nanofiltered C1-INH.

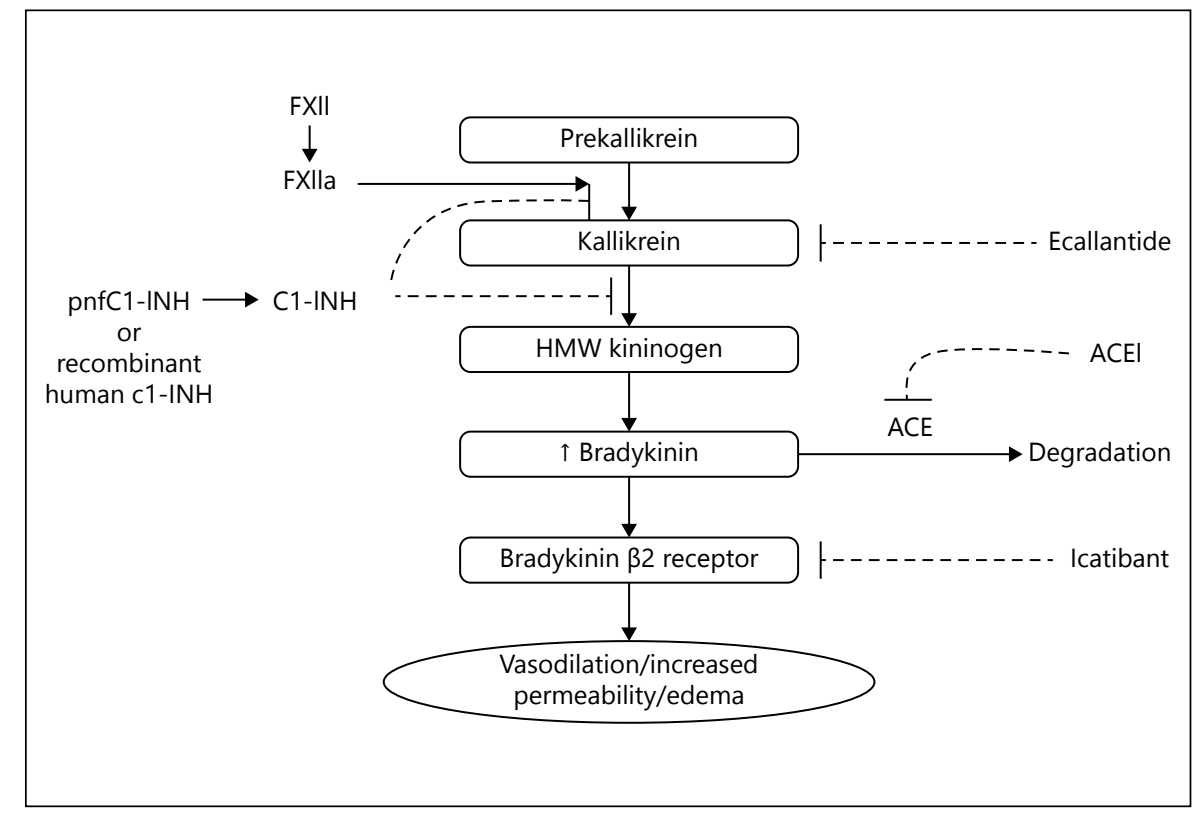

cessful in the treatment of HAE types I/II for many years [1]. However, for other forms of bradykinin-mediated angioedema, the diagnostic and treatment needs are less well understood. Bradykinin-mediated forms of angioedema include both hereditary, i.e. HAE types I and II, and nonheredity forms, i.e. acquired angioedema with C1-INH deficiency [2]. During bradykinin-mediated angioedema, increased levels of bradykinin results in overactivation of $\beta 2$ bradykinin receptors and subsequently increased tissue permeability, vasodilation and edema (fig. 1). Bradykinin-mediated forms of angioedema are distinct from allergic reactions, as they do not respond to conventional therapies such as antihistamines or corticosteroids.

To address these points, a group of international angioedema experts gathered in Budapest in May 2013 to present their experience, review available literature and explore the feasibility of using medications approved for HAE types I and II in the treatment of other forms of angioedema. The HAE expert group explored three other forms of bradykinin-mediated angioedema: HAE with normal C1-INH (HAE-nC1-INH), formerly referred to as type III HAE, which can result from FXII mutations (FXII-HAE) or an unknown cause (U-HAE), nonallergic angiotensin-converting enzyme inhibitor (ACEI)-induced angioedema (ACEI-AAE), and acquired angioedema due to C1-INH deficiency (C1-INH-AAE) [3]. For these forms of angioedema there are currently no licensed treatments available, and no improvements are observed with conventional antihistamine/glucocorticoid treatment. Furthermore, in these forms of angioedema, C1INH antigenic levels and function may be normal and there may be no family history which can make diagnosis of these forms difficult.

Here we report on the findings of the HAE expert meeting and summarize the thoughts and opinions of HAE experts on the key characteristics (table 1) and challenges associated with diagnosing these forms of angioedema. We present evidence from the HAE expert meeting that suggest that treatments, such as $\mathrm{C} 1-\mathrm{INH}$, which are used in the treatment of HAE I/II may be beneficial in the treatment of FXII-HAE/U-HAE, ACEI-AAE and C1INH-AAE.

\section{Challenges Associated with Diagnosing Alternative Forms of Angioedema}

During the angioedema expert meeting, participants stressed the importance of ensuring that the exact medical condition is treated. Allergic forms of angioedema are histamine dependent and can often be determined by the presence of urticaria and successful treatment with antihistamines/glucocorticoids. Since the majority of cases are histamine dependent, it was uniformly agreed that initial cases of angioedema should be treated as such and given short-term treatment with antihistamines/glucocorticoids. An alternate diagnosis should be established 
Table 1. Characteristics of hereditary, nonallergic drug-induced and acquired forms of angioedema

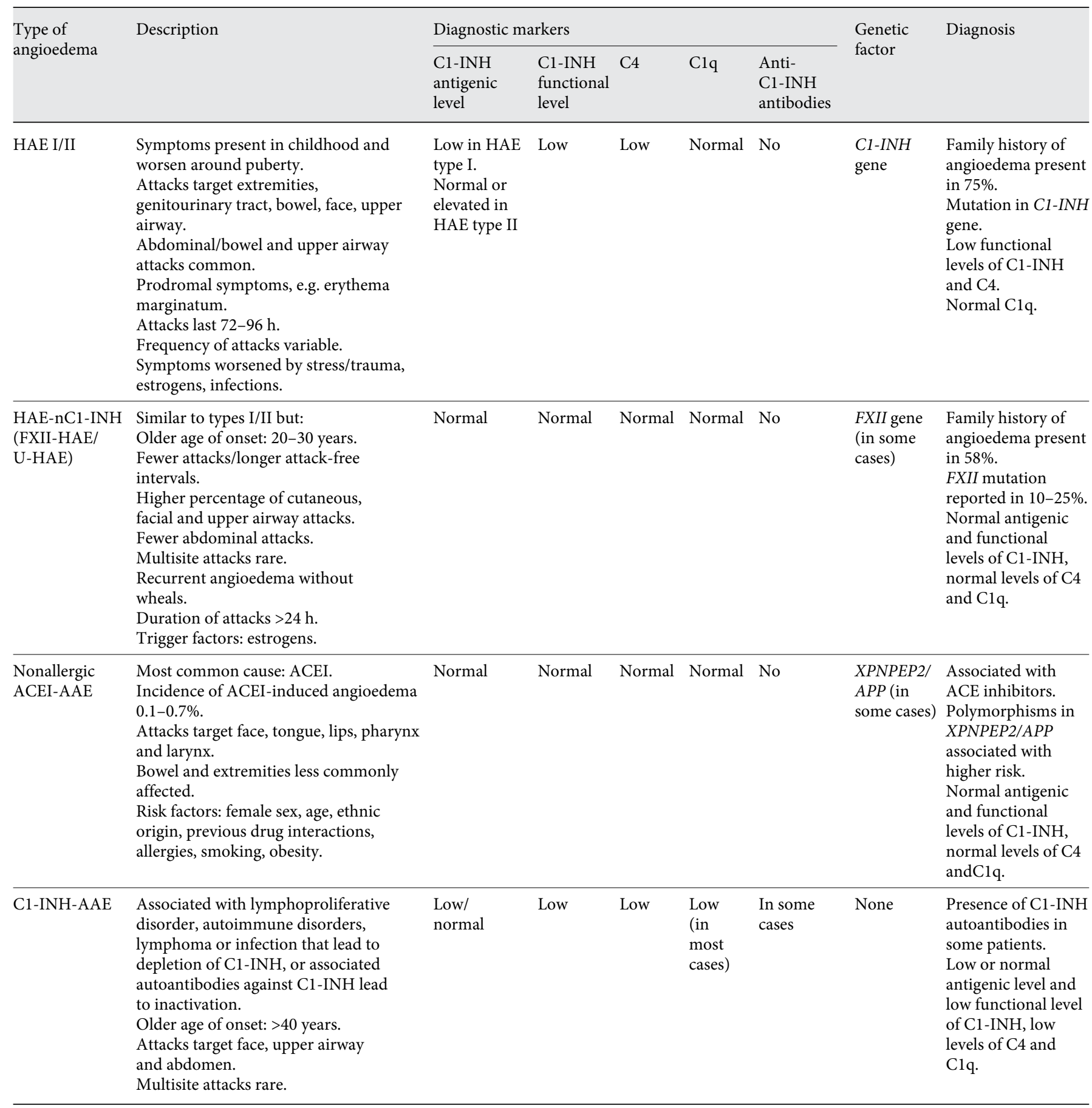

in cases that are nonresponsive to short-term treatment with antihistamines/glucocorticoids. Diagnostic tests investigating $\mathrm{C} 1-\mathrm{INH}, \mathrm{Clq}$ or $\mathrm{C} 4$ levels could be used as a diagnostic tool; however, these may not always indicate if attacks are histamine or bradykinin induced (table 1).

\section{HAE with Normal C1-INH}

In FXII-HAE/U-HAE, antigenic and functional levels of $\mathrm{C} 1-\mathrm{INH}, \mathrm{Clq}$ and $\mathrm{C} 4$ are normal, so diagnostic testing using these markers cannot be used. FXII-HAE/U-HAE can be characterized by recurrent angioedema attacks 
without wheals, a prolonged duration of attacks, an older age of symptom onset, with the mean age of first attack $26.8 \pm 14.9$ years, and a higher percentage of facial attacks $[2,4]$. Furthermore, key differentiating factors for FXII$\mathrm{HAE} / \mathrm{U}-\mathrm{HAE}$ are that it can be triggered by estrogens [4, $5]$ and has been associated with mutations in the FXII gene $[6-8]$.

Exposure to estrogens, either during pregnancy or from oral contraceptives, has been shown to exacerbate the severity of attacks in many FXII-HAE/U-HAE patients $[4,9]$. Furthermore, a subset of FXII-HAE/U-HAE patients has been shown to be estrogen-dependent, i.e. swelling only occurs at the time of estrogen exposure. Angioedema expert discussion of unpublished experience identified that $80 \%$ of French cases worsened with estrogen, $13 \%$ of cases were estrogen dependent (only occurring with contraceptive use or pregnancy), and only $7 \%$ of cases were not influenced by estrogen (as presented at the 8th C1-INH deficiency workshop [10]). However, this is in contrast to the experience of other experts at the meeting; in a Spanish cohort the majority of patients (85\%) were estrogen dependent, and 15\% were estrogen related (as presented at the 8th C1-INH deficiency workshop [10]). Furthermore, published data from Vitrat-Hincky et al. [5] observed that the condition of $54.5 \%$ of women worsened with estrogen, and $23 \%$ were estrogen dependent [11]. These data highlight that the influence of estrogen on FXII-HAE/U-HAE is highly variable.

Several mechanisms have been proposed for the estrogen dependence observed in FXII-HAE/U-HAE that involve the effects of estrogen on both bradykinin production and degradation. High levels of estrogen that occur during pregnancy or from oral contraceptive use have been shown to increase the level of FXII due to an estrogen response element in the gene promoter. As illustrated in figure 1, FXII, when activated, converts prekallikrein to kallikrein; the first step in bradykinin production and increased FXII could result in increased bradykinin production. Additionally, under high-estrogen conditions, levels of C1-INH have been shown to decrease, which would reduce inhibition of FXII and kallikrein and further promote increased bradykinin production (fig. 1). High levels of estrogen may also reduce the degradation of bradykinin through inhibition of angiotensin-converting enzyme (ACE) expression and possibly through a reduction of aminopeptidase P (APP) levels [12].

Although FXII-HAE/U-HAE has been associated with mutations in the FXII gene; mutations are only found in a small subset of patients [4] and symptoms in patients with or without FXII mutations are similar [11, 13]. During the meeting it was reported that only 10 $25 \%$ of diagnosed French patients have a FXII mutation. Furthermore, $42 \%$ of patients had no family history and disease symptoms can be highly variable. To illustrate this, a case report was presented of a female FXII mutation carrier who experienced recurrent abdominal attacks throughout puberty and pregnancy, together with some additional peripheral attacks. In contrast, her sister, also an FXII mutation carrier, only suffered attacks during pregnancy, and her mutation-carrying daughters are asymptomatic. The low percentage of FXII mutation carriers led to the question of how patients can be reliably identified by genotyping alone, and may explain the variability in incidence across other countries, for example American angioedema experts highlighted that patients with normal C1-INH levels and no family history of angioedema would not be genotyped, thus few cases of FXII-HAE/U-HAE are reported there. Diagnosis of FXII-HAE/U-HAE therefore depends upon the interplay between genetic, clinical and laboratory factors, and key criteria to monitor include recurrence of angioedema attacks, near normal C1-INH, C1q and C4, evidence of estrogen dependence and evidence of FXII mutations or family history.

\section{ACEI-Induced Angioedema}

In ACEI-AAE, levels of C1-INH, C4 and C1q are normal and attacks commonly affect the head and neck, and can involve the mouth, tongue and larynx, which can lead to fatal laryngeal obstruction. ACE is an important regulator of bradykinin levels involved in the cleavage and degradation of bradykinin (fig. 1). In the presence of ACEIs, degradation of bradykinin is dependent upon APP, neutral endopeptidase (NEP) and dipetidyl peptidase IV (DPP-IV), and the blood and tissue levels of these enzymes are important factors in the prevention of ACEI-AAE [14]. The reported incidence of ACE-AAE is $0.1-2 \%$ [14]; however, some populations, such as African Americans, women and smokers, have a higher risk of developing ACEI-AAE [2].

Polymorphisms in XPNPEP2 $[15,16]$ and haplotype mutations in the $A P P$ gene $[15,17]$ have been identified as possible risk factors of ACEI-AAE; however, there is no clear genetic basis for the disease. XPNPEP2 encodes APP, which is involved in the cleavage and inactivation of bradykinin. Polymorphisms in XPNPEP2 have been linked with an increased risk, especially in black (African) women $[15,18]$. The increased incidence reported among African Americans and women may be due to reduced 
plasma activity and levels of APP [15]. On reviewing data from the University of Cincinnati on ACEI-induced angioedema, $75 \%$ of patients presenting to the emergency department were African American. Due to the complex genetic background the question remains as to whether genotyping would be beneficial in identifying high-risk patients.

The risk of ACEI-AAE is also increased in patients receiving treatment with DPP-IV inhibitors that are used to treat diabetes, or NEP inhibitors used to treat hypertension [14]. A clinical study of patients receiving omapatrilat, an NEP inhibitor currently under development, found that it was more frequently associated with angioedema than the ACE inhibitor enalapril (2.17 vs. $0.68 \%$ ) [19]. A premarketing study of the DPP-IV inhibitor vildagliptin found that whilst there was no association between vildagliptin treatment alone and angioedema, use of vildagliptin alongside ACEI resulted in a small increased risk of angioedema, as shown by 14 confirmed angioedema cases amongst 2,754 vildagliptin patients compared to 1 amongst 1,819 in a comparator product (odds ratio 4.57; 95\% CI 1.57-13.28) [20].

ACEI-AAE often occurs early in the course of ACEI treatment, with around $50 \%$ of cases occurring in the first week of treatment $[14,21]$; however, it can occur several months or years after initial treatment [2]. While most attacks resolve within $24-48 \mathrm{~h}$ of discontinuation of ACEI, they can recur weeks or months after treatment discontinuation [15]. The variable time between the start of ACEI treatment and attack is another factor that can complicate the diagnosis of ACEI-AAE.

Acquired Angioedema due to C1-INH Deficiency

$\mathrm{C} 1-\mathrm{INH}-\mathrm{AAE}$ is associated with lymphoproliferative disorders such as monoclonal gammopathy of uncertain significance, malignant lymphoma, neoplasm, infections and autoimmune disorders. C1-INH-AAE can be characterized by large-scale activation of complement pathways and a breakdown of C1-INH $[22,23]$. A reduction in C1INH may be via an interaction with lymphatic tissues which have been shown to consume C1-INH [24]. In some cases $\mathrm{C} 1$-INH-AAE may result from autoantibodies against C1-INH [22]. Anti-C1-INH antibodies bind to $\mathrm{C} 1-\mathrm{INH}$ and prevent the formation of $\mathrm{C} 1-\mathrm{INH}$ protein complexes. The presence of autoantibodies can also convert C1-INH into a substrate for proteases which results in cleavage of C1-INH $[22,24]$. This leads to depletion of components of the complement system, resulting in low antigenic levels and low functional levels of C1-INH, low levels of $\mathrm{C} 4$ and, in most cases, low $\mathrm{C1q}$ [2]. As C1-INHAAE is associated with low $\mathrm{C} 1-\mathrm{INH}$, its clinical presentation is similar to HAE types I/II. However, unlike HAE forms, C1-INH-AAE is not associated with an inherited condition so has no family history [2] and is associated with a later age of symptom onset, typically in the 4th or 5 th decade of life [2]. In 4 cases presented at the angioedema expert meeting, no patients had a family history of angioedema, 2 patients had autoantibodies against C1INH and all patients had underlying lymphoproliferative disease ( 3 with non-Hodgkin's lymphoma, 1 with multiple myeloma).

Diagnosis is usually made by laboratory testing that identifies low $\mathrm{C} 4, \mathrm{C} 1-\mathrm{INH}$ and low $\mathrm{C} 1-\mathrm{INH}$ function. $\mathrm{C} 1 \mathrm{q}$ is low in most cases and helps distinguish C1-INHAAE from HAE types I/II; nevertheless, not all cases have low $\mathrm{Clq}$, making differential diagnoses difficult. In these cases, genetic analysis to differentiate the hereditary from the acquired form may assist with diagnosis [22]. The presence of autoantibodies against C1-INH may be an indicator of C1-INH-AAE [2], although they are only observed in $70 \%$ of patients [25] and thus are not always present, as demonstrated by the cases discussed by the expert group.

\section{Unmet Treatment Needs: The Current Therapeutic Landscape}

Currently, there are no approved therapies for FXIIHAE/U-HAE, ACEI-AAE or C1-INH-AAE. Participant experience and unpublished case studies discussed during the meeting showed that therapies approved for use in HAE types I/II, including pasteurized, nanofiltered C1-INH (pnfC1-INH, Berinert; CSL Behring, Marburg, Germany), ecallantide (Kalbitor; Dyax, Burlington, Mass., USA) and icatibant (Firazyr; Shire Orphan Therapies $\mathrm{GmbH}$, Berlin, Germany), have successfully resolved attacks of different types of bradykinin-induced angioedema. Icatibant, ecallantide and C1-INH have been shown to be effective treatments for ACEI-AAE $[15,26]$, C1-INH-AAE $[2,27]$ and FXII-HAE/U-HAE [9] (table 2), and are currently the focus of ongoing clinical trials in the USA $[28,29]$. Fresh frozen plasma (FFP) has been successfully used in the treatment of FXII-HAE/UHAE $[2,30]$ and ACEI-AAE $[2,15]$, and has been recommended as a treatment for angioedema when no specific treatment options are available [2]. However, the use of FFP was discussed during the HAE expert meeting as, although FFP is a successful treatment option for angio- 


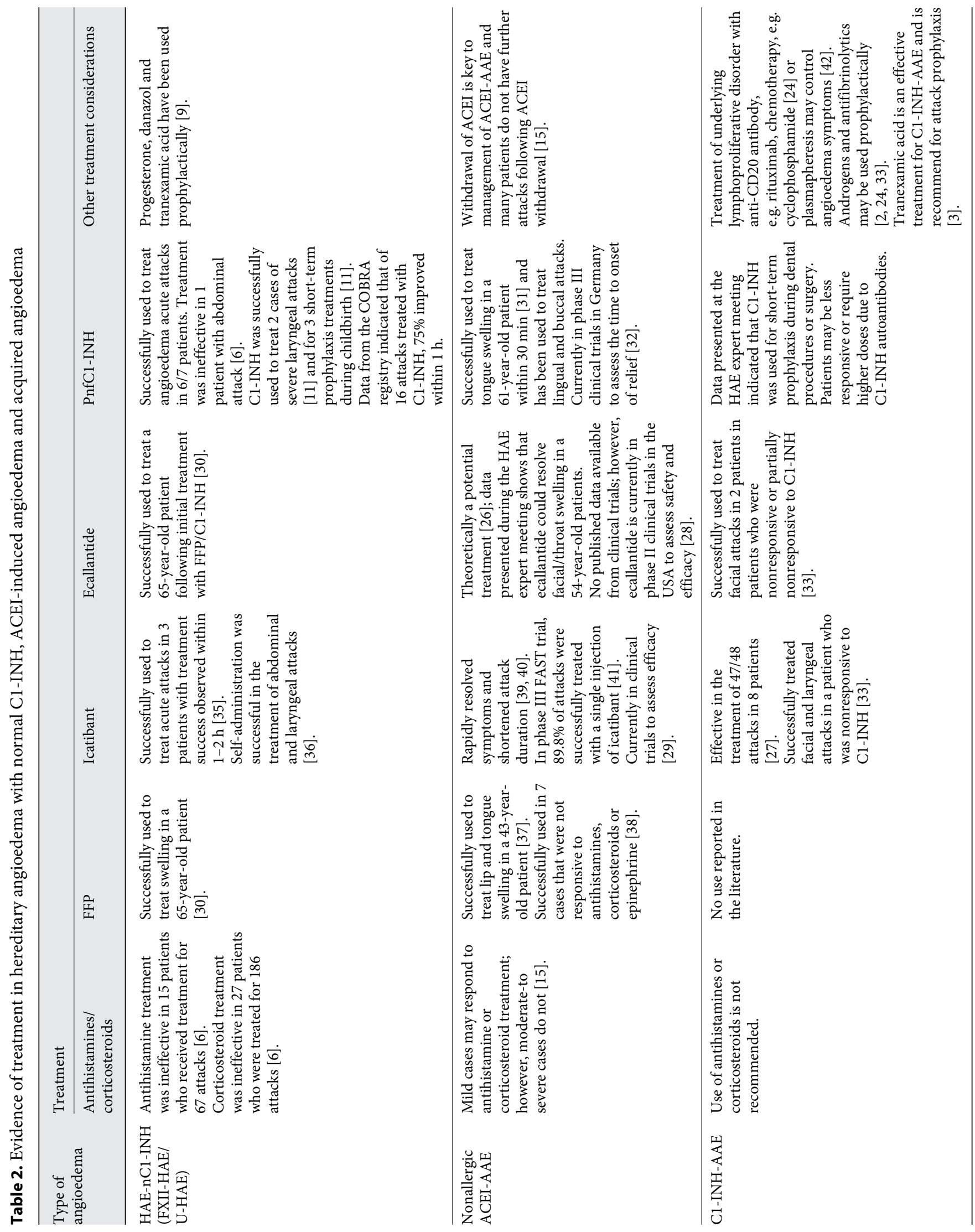


edema due to the presence of angiotensin II in plasma that acts to degrade bradykinin [15], it should be used with caution for acute treatment of angioedema attacks due to the presence of substrate, which may exacerbate swelling $[2,15]$. In countries where other options are available, FFP is not recommended due to the presence of substrate and because it carries a small risk of viral transmission $[2,3]$, as with other plasma-derived products.

During the HAE expert meeting several case studies on the use of C1-INH in alternative angioedema types were presented. For FXII-HAE/U-HAE, there are limited data available on the therapeutic efficacy of treatments [26]; however, C1-INH has been shown to be moderately or very effective in most patients when used to treat laryngeal attacks [11], for short-term prophylaxis [11] or when used to treat acute attacks in patients with FXII mutations [6]. In the case study reported at the angioedema expert meeting, a patient with the FXII mutation was successfully treated with pnfC1-INH for edematous attacks during pregnancy and for short-term prophylaxis during delivery. French patients who suffered frequent attacks ( $\geq 7.2 /$ year) were treated with pnfC1-INH (7\%) and a small number of patients received pnfC1-INH prophylactically. The national French registry, COBRA (the French National Center for Bradykinin-Mediated Angioedema), includes patients with FXII-HAE/U-HAE who have been treated with pnfC1-INH. So far, 16 attacks have been successfully treated, with $75 \%$ of patients showing improvements within the first hour after administration.

Several case reports of ACEI-AAE were presented at the angioedema expert meeting. The effectiveness of pnfC1-INH was illustrated in a case study [31] and in a small open-label study where lingual and buccal attacks resolved. A randomized, double-blind, multicenter phase III trial of pnfC1-INH in ACEI-AAE is currently underway in Germany to assess the time to complete resolution of signs and symptoms of acute ACE-induced angioedema of the upper airway tract compared to placebo when given on top of standard treatment [32].

For C1-INH-AAE, all 4 unpublished cases discussed at the meeting were successfully treated with pnfC1-INH and 2 patients were prophylactically treated with pnfC1INH prior to dental procedures. Additionally, it was noted that some patients, particularly those with autoantibodies, required higher doses of pnfC1-INH. This could be due to patients with autoantibodies becoming resistant to $\mathrm{C} 1-\mathrm{INH}$ treatment $[2,22,24]$; in these patients, C1INH-AAE can be successfully treated with icatibant or ecallantide [27]. C1-INH-AAE is linked to lymphoprolif-

Diagnosis and Treatment of Angioedema other than HAE erative diseases, and it has been observed that cytotoxic treatment of the lymphoproliferative diseases associated with C1-INH-AAE variably reverses the complement impairment, leading to improvement of the angioedema symptoms [24].

The question of why C1-INH treatment would be effective in forms of angioedema in which C1-INH levels are normal was raised by some angioedema experts. During the discussion participants proposed that, mechanistically, treatment with $\mathrm{C} 1-\mathrm{INH}$ concentrate might prevent further production of bradykinin, although it was suggested that there may be a latency in response due to the time taken to metabolize preexisting bradykinin (fig. 1).

\section{Discussion}

The angioedema expert group identified unmet diagnostic and treatment needs in FXII-HAE/U-HAE, ACEI$A A E$ and C1-INH-AAE. In particular, they noted that diagnostic markers such as levels of $\mathrm{C} 1-\mathrm{INH}, \mathrm{C} 4$ or $\mathrm{Clq}$ cannot be reliably used to differentiate between angioedema types. For FXII-HAE/U-HAE and ACEI-AAE the levels of $\mathrm{C} 1-\mathrm{INH}, \mathrm{C} 4$ and $\mathrm{C} 1 \mathrm{q}$ are normal but complementary testing may be useful to provide a differential diagnosis from HAE types I/II. The presentation of C1INH-AAE is similar to HAE type I/II, so differentiating these types can be difficult using diagnostic markers; low $\mathrm{C} 1-\mathrm{INH}$ and $\mathrm{C} 4$ levels are expected, but C1q may be normal. If the C1q level is normal ( $30 \%$ of cases) [33], genetic testing can distinguish between C1-INH-AAE and HAE types I/II; however, mutation of the C1-INH gene cannot be detected in $8-10 \%$ of cases of HAE types I/II [34]. The presence of autoantibodies in C1-INH-AAE may be a useful diagnostic marker, although these are not present in all cases.

The expert consensus was that more definitive testing is essential for angioedema, not only to determine bradykinin- from histamine-induced angioedema, but also to distinguish different types of bradykinin-induced angioedema. Definitive treatment for FXII-HAE/ U-HAE and other angioedema types will require tests that can confirm the diagnosis. Whilst there are currently no approved therapies for FXII-HAE/U-HAE, ACEI-AAE and C1-INH-AAE, evidence presented during the HAE expert meeting indicated that therapies such as $\mathrm{C} 1-\mathrm{INH}$, icatibant and ecallantide can be effective. Further data from clinical studies are needed to confirm the efficacy of the medications discussed above 
in bradykinin-induced diseases other than HAE types I/ II; however, several promising trials in ACEI-AAE are currently ongoing.
- FXII-HAE/U-HAE has a positive family history, symptom onset is most often at age 20-30 years, it is largely associated with estrogens and is observed in patients with or without mutation in the FXII gene.

\section{Key Clinical Points}

The following key clinical points were agreed upon at the meeting:

- ACEIs are the leading cause of drug-induced angioedema.

- C1-INH-AAE is not associated with a hereditary C1-INH deficiency, is often associated with a C1-INH autoantibody and a low C1, and occurs most commonly in patients aged $>40$ years.

\section{Acknowledgements}

The authors would like to thank all participants of the international angioedema expert meeting for the stimulating discussion and exchange of knowledge that took place during the meeting. The international angioedema expert meeting and the preparation of this article were supported by CSL Behring. Editorial assistance was provided by Meridian HealthComms, Plumley, UK.

\section{References}

1 Bork K, Steffensen I, Machnig T: Treatment with C1-esterase inhibitor concentrate in type I or II hereditary angioedema: a systematic literature review. Allergy Asthma Proc 2013;34: 312-327.

-2 Lang DM, Aberer W, Bernstein JA, Chng HH, Grumach AS, Hide M, Maurer M, Weber R, Zuraw B: International consensus on hereditary and acquired angioedema. Ann Allergy Asthma Immunol 2012;109:395-402.

-3 Cicardi M, Aberer W, Banerji A, Bas M, Bernstein JA, Bork K, Caballero T, Farkas H, Grumach A, Kaplan AP, Riedl MA, Triggiani M, Zanichelli A, Zuraw B: Classification, diagnosis, and approach to treatment for angioedema: consensus report from the Hereditary Angioedema International Working Group Allergy 2014;69:602-616.

4 Zuraw BL, Bork K, Binkley KE, Banerji A, Christiansen SC, Castaldo A, Kaplan A, Riedl M, Kirkpatrick C, Magerl M, Drouet C, Cicardi M: Hereditary angioedema with normal C1 inhibitor function: consensus of an international expert panel. Allergy Asthma Proc 2012;33(suppl 1):S145-S156.

5 Vitrat-Hincky V, Francois P, Labarere J, Recule C, Stahl JP, Pavese P: Appropriateness of blood culture testing parameters in routine practice: results from a cross-sectional study. Eur J Clin Microbiol Infect Dis 2011;30:533539.

6 Bork K, Wulff K, Hardt J, Witzke G, Staubach $P$ : Hereditary angioedema caused by missense mutations in the factor XII gene: clinical features, trigger factors, and therapy. J Allergy Clin Immunol 2009;124:129-134.

7 Cichon S, Martin L, Hennies HC, Muller F, van Driessche K, Karpushova A, Stevens W, Colombo R, Renne T, Drouet C, Bork K, Nothen MM: Increased activity of coagulation factor XII (Hageman factor) causes hereditary angioedema type III. Am J Hum Genet 2006; 79:1098-1104.

8 Dewald G, Bork K: Missense mutations in the coagulation factor XII (Hageman factor) gene in hereditary angioedema with normal $\mathrm{C} 1$ inhibitor. Biochem Biophys Res Commun 2006; 343:1286-1289.

9 Bork K: Diagnosis and treatment of hereditary angioedema with normal $\mathrm{C} 1$ inhibitor. Allergy Asthma Clin Immunol 2010;6:15.

10 Farkas H, Varga L: Abstracts of the 8th C1Inhibitor Deficiency Meeting, Budapest, Hungary. J Angioedema 2013;1:1-51.

11 Vitrat-Hincky V, Gompel A, Dumestre-Perard C, Boccon-Gibod I, Drouet C, Cesbron JY, Lunardi J, Massot C, Bouillet L: Type III hereditary angio-oedema: clinical and biological features in a French cohort. Allergy 2010; 65:1331-1336.

12 Binkley KE: Factor XII mutations, estrogendependent inherited angioedema, and related conditions. Allergy Asthma Clin Immunol 2010;6:16.

13 Bork K, Gul D, Hardt J, Dewald G: Hereditary angioedema with normal $\mathrm{C} 1$ inhibitor: clinical symptoms and course. Am J Med 2007; 120:987-992.

14 Kaplan A: Drug-induced angioedema. J Angioedema 2011;1:14-22.

15 Campo P, Fernandez TD, Canto G, Mayorga C: Angioedema induced by angiotensin-converting enzyme inhibitors. Curr Opin Allergy Clin Immunol 2013;13:337-344.

16 Mahmoudpour SH, Leusink M, van der Putten L, Terreehorst I, Asselbergs FW, de Boer A, Maitland-van der Zee AH: Pharmacogenetics of ACE inhibitor-induced angioedema and cough: a systematic review and metaanalysis. Pharmacogenomics 2013; 14:249260.

17 Cilia La Corte AL, Carter AM, Rice GI, Duan QL, Rouleau GA, Adam A, Grant PJ, Hooper NM: A functional XPNPEP2 promoter haplotype leads to reduced plasma aminopeptidase $\mathrm{P}$ and increased risk of ACE inhibitor-induced angioedema. Hum Mutat 2011;32: 1326-1331.

18 Woodard-Grice AV, Lucisano AC, Byrd JB, Stone ER, Simmons WH, Brown NJ: Sex-de- pendent and race-dependent association of XPNPEP2 C-2399A polymorphism with angiotensin-converting enzyme inhibitor-associated angioedema. Pharmacogenet Genomics 2010;20:532-536.

19 Kostis JB, Packer M, Black HR, Schmieder R, Henry D, Levy E: Omapatrilat and enalapril in patients with hypertension: the Omapatrilat Cardiovascular Treatment versus Enalapril (OCTAVE) trial. Am J Hypertens 2004; 17: 103-111.

20 Brown NJ, Byiers S, Carr D, Maldonado M, Warner BA: Dipeptidyl peptidase-IV inhibitor use associated with increased risk of ACE inhibitor-associated angioedema. Hypertension 2009;54:516-523.

21 Sabroe RA, Black AK: Angiotensin-converting enzyme (ACE) inhibitors and angio-oedema. Br J Dermatol 1997;136:153-158.

22 Caballero T, Baeza ML, Cabanas R, Campos A, Cimbollek S, Gomez-Traseira C, Gonzalez-Quevedo T, Guilarte M, Jurado-Palomo GJ, Larco JI, Lopez-Serrano MC, LopezTrascasa M, Marcos C, Munoz-Caro JM, Pedrosa M, Prior N, Rubio M, Sala-Cunill A: Consensus statement on the diagnosis, management, and treatment of angioedema mediated by bradykinin. Part I. Classification, epidemiology, pathophysiology, genetics, clinical symptoms, and diagnosis. J Investig Allergol Clin Immunol 2011;21:333-347.

23 Zingale LC, Castelli R, Zanichelli A, Cicardi $\mathrm{M}$ : Acquired deficiency of the inhibitor of the first complement component: presentation, diagnosis, course, and conventional management. Immunol Allergy Clin North Am 2006; 26:669-690.

24 Castelli R, Zanichelli A, Cicardi M, Cugno M: Acquired C1-inhibitor deficiency and lymphoproliferative disorders: a tight relationship. Crit Rev Oncol Hematol 2013;87:323332 .

25 Cicardi M, Zanichelli A: Angioedema due to C1 inhibitor deficiency in 2010. Intern Emerg Med 2010;5:481-486. 
26 Farkas H: Current pharmacotherapy of bradykinin-mediated angioedema. Expert Opin Pharmacother 2013;14:571-586.

-27 Zanichelli A, Bova M, Coerezza A, Petraroli A, Triggiani M, Cicardi M: Icatibant treatment for acquired C1-inhibitor deficiency: a real-world observational study. Allergy 2012; 67:1074-1077.

28 Clinical Trials: Evaluation of ecallantide for the acute treatment of angiotensin converting enzyme inhibitor induced angioedema. http://clinicaltrials.gov/show/NCT01036659 (accessed August 4, 2014).

29 Clinical Trials: Effect of bradykinin receptor antagonism on ACE inhibitor-associated angioedema. http://clinicaltrials.gov/show/ NCT01574248 (accessed August 4, 2014).

30 Lumry WR: A report from ACAAI: highlights of presentations given at the 2012 Annual Meeting of the American College of Allergy, Asthma and Immunology (ACAAI). J Angioedema 2013;1:1-12.

31 Nielsen EW, Gramstad S: Angioedema from angiotensin-converting enzyme (ACE) inhibitor treated with complement 1 (C1) inhibitor concentrate. Acta Anaesthesiol Scand 2006; 50:120-122.
32 Clinical Trials: Randomized, double-blind, two arms, multicenter, phase III study of berinert for treatment of ACE induced angioedema. http://clinicaltrials.gov/show/NCT01843530 (accessed August 4, 2014).

33 Cicardi M, Zanichelli A: Acquired angioedema. Allergy Asthma Clin Immunol 2010;6:14.

34 Craig T, Aygoren-Pursun E, Bork K, Bowen T, Boysen H, Farkas H, Grumach A, Katelaris $\mathrm{CH}$, Lockey R, Longhurst H, Lumry W, Magerl M, Martinez-Saguer I, Ritchie B, Nast A, Pawankar R, Zuraw B, Maurer M: WAO guideline for the management of hereditary angioedema. World Allergy Organ J 2012;5: 182-199.

35 Bouillet L, Boccon-Gibod I, Ponard D, Drouet C, Cesbron JY, Dumestre-Perard C, Monnier N, Lunardi J, Massot C, Gompel A: Bradykinin receptor 2 antagonist (icatibant) for hereditary angioedema type III attacks. Ann Allergy Asthma Immunol 2009; 103:448.

36 Boccon-Gibod I, Bouillet L: Safety and efficacy of icatibant self-administration for acute hereditary angioedema. Clin Exp Immunol 2012;168:303-307.

37 Warrier MR, Copilevitz CA, Dykewicz MS, Slavin RG: Fresh frozen plasma in the treatment of resistant angiotensin-converting enzyme inhibitor angioedema. Ann Allergy Asthma Immunol 2004;92:573-575.
38 Hassen GW, Kalantari H, Parraga M, Chirurgi R, Meletiche C, Chan C, Ciarlo J, Gazi F, Lobaito C, Tadayon S, Yemane S, Velez C: Fresh frozen plasma for progressive and refractory angiotensin-converting enzyme inhibitor-induced angioedema. J Emerg Med 2013;44:764-772.

39 Bas M, Greve J, Stelter K, Bier H, Stark T, Hoffmann TK, Kojda G: Therapeutic efficacy of icatibant in angioedema induced by angiotensin-converting enzyme inhibitors: a case series. Ann Emerg Med 2010;56:278282.

40 Gallitelli M, Alzetta M: Icatibant: a novel approach to the treatment of angioedema related to the use of angiotensin-converting enzyme inhibitors. Am J Emerg Med 2012;30: 1664.e1-2.

41 Bas M, Greve J, Hoffmann TK, Reshef A, Aberer W, Maurer M, Kivity S, Farkas H, Floccard B, Arcoleo F, Martin L, Sitkauskiene B, Bouillet L, Schmid-Grendelmeier P, Li H, Zanichelli A: Repeat treatment with icatibant for multiple hereditary angioedema attacks: FAST-2 open-label study. Allergy 2013;68: 1452-1459.

42 Kaplan AP: Angioedema. World Allergy Organ J 2008;1:103-113. 